Volume 6, No. 1 January - March 2020 www.jrmi.pk

\title{
Spectrum of postoperative complications and histopathological findings of appendectomy in Rehman Medical Institute from 2017-2018
}

\author{
Zubair Ahmad Khan, Hamza Ateeq, Hira Shamim, Waqas Zahid, Shazma Majeed, Aimen Saeed, \\ Sahal Arshad
}

\section{Submitted}

December 14, 2019

Accepted

January 22,2020

\section{Author Information}

Dr. Zubair Ahmad Khan

Associate Professor \&

Consultant General and

Laparoscopic Surgeon,

Rehman Medical Institute

Peshawar, Khyber

Pakhtunkhwa, Pakistan

(Corresponding Author)

Email:

zubair.khan@rmi.edu.pk

Hamza Ateeq

Hira Shamim

Waqas Zahid

Shazma Majeed

Aimen Saeed

Sahal Arshad

Final Year MBBS Students, Rehman Medical College,

Peshawar, Khyber

Pakhtunkhwa, Pakistan

Citation: Khan ZA, Ateeq H, Shamim H, Zahid W, Majeed

S, Saeed A, et al. Spectrum of postoperative complications and histopathological findings of appendectomy in Rehman Medical Institute from 20172018. J Rehman Med Inst. 2020 Jan-Mar;6(1):16-9.

\section{ABSTRACT}

Introduction: Documentation of postappendectomy complications along with histopathological findings help in clinical management of acute appendicitis.

Objective: To determine the postoperative complications occurring in appendectomy patients of a tertiary care hospital of Peshawar, Khyber Pakhtunkhwa, based on two-years archival data.

Materials \& Methods: A descriptive study was conducted at Rehman Medical Institute, Peshawar, from January to February 2019 on 130 archival cases of appendectomies done from 2017-2018 to document postoperative complications and histopathological findings. Data were collected on a structured Performa consisted of demographic data, symptoms, complications, investigations performed, preoperative position of appendix, pathology and comorbidities. Descriptive data analysis was done with SPSS 25.0.

Results: The most common age group for acute appendicitis was 19 years $(n=9,6.9 \%)$ followed by 40 years $(n=8,6.2 \%)$; more patients were males $(\mathrm{n}=73,56.15 \%)$ compared to females, $(\mathrm{n}=57$, $43.85 \%$ ). Patients presented with the common complaint of pain in right iliac fossa with nausea, $(n=102, \quad 78.5 \%)$, followed by generalized abdominal pain $(n=20,15.4 \%)$ and epigastric pain and vomiting $(n=8,6.2 \%)$. Retrocecal appendix was the most frequent site $(75.4 \%) ; 52.3 \%$ of patients did not develop any postoperative complication.

Conclusion: Wound infection and pain were the commonest complications after surgery. Malignancy was rare.

Keywords: acute appendicitis, postoperative complications, histopathological finding, wound infection.

The authors declared no conflict of interest. All authors contributed substantially to the planning of research, data collection, data analysis, and write-up of the article, and agreed to be accountable for all aspects of the work.

\section{INTRODUCTION}

Acute appendicitis is the utmost common surgical ailment, with an occurrence of about 100 per 100,000. The lifetime risk of developing appendicitis is approximately $9 \%$ in males and $7 \%$ in females. ${ }^{1}$ Initial findings and quick operative interventions are keys to effective management of acute appendicitis.

Acute appendicitis is the most often assumed condition in patients presenting with acute abdominal pain, hence the most common indication for emergency abdominal surgery. Luminal obstructions due to fecoliths, hyperplasia of the lymphoid tissue, or foreign bodies are the most common causes of acute appendicitis. However, often the exact cause behind appendicitis remains unknown. The signs and symptoms are usually anorexia, periumbilical colic, nausea and vomiting, followed by moderate fever $\left(38^{\circ} \mathrm{C}\right)$ and signs of peritoneal inflammation in the lower right quadrant of the abdomen. Changes consistent with acute inflammation (acute appendicitis, acute suppurative appendicitis, gangrenous appendicitis, and peri-appendicular abscess) were reported in $79.5 \%$ cases.

Complications such as perforation, peritonitis, appendicular mass and abscess, resulting from the acute inflammatory process are serious, making early surgery fundamental. ${ }^{2}$ Post-appendectomy complications are peritonitis, wound infection, lack of intestinal peristalsis, surgical injuries to internal organs, bowel obstruction, gangrene of the bowel, and abscess. Perforation is the major reason of morbidity and mortality. Postoperative complications in appendectomy were $29 \%$ recorded from February 2004-January 2005 by Division of Gastrointestinal Surgery, Wolfson Digestive Disease Centre, Nottingham University Hospitals, Queen's Medical Centre, Nottingham, $\mathrm{UK}^{3}$ In a study it was recorded that $1.1 \%$ patients with non-complex acute appendicitis patients got infectious complications after receiving laparoscopic treatment compared to $1.6 \%$ of patients with gangrenous acute appendicitis. Studies conducted in China and Istanbul showed that there were $6.2 \%$ and $3 \%$ overall surgical site infections respectively, after appendectomy. ${ }^{4,5}$ 
Complications of acute appendicitis are so risky that surgical removal of appendix is usually preferred by surgeon. The fear of a perforated appendicitis has led the surgeons to accept the possibility of removal of an unaffected appendix so that even up to $30 \%$ negative appendectomies are acceptable. ${ }^{6}$

Laparoscopic appendectomy has been recognized as the preferred surgery in pediatric cases of acute appendicitis due to earlier discharge from the hospitals, getting back to normal appetite and lifestyle, along with reduced morbidity. ${ }^{7,8}$ Reports have shown that intra-abdominal abscess occurs in $6.4-15 \%$ children who underwent laparoscopic appendectomy. Other reports show that about $2 \%$ cases of acute non-complex appendicitis have an incidence of intraabdominal abscess compared to $24-41 \%$ cases of perforated appendicitis. ${ }^{8-12}$

Some reports show that the actions of bacteria at the site of surgery related to the use of different instruments have led to different postoperative complications of appendicitis; local interstitial infection in the ileocecal area may cause intraabdominal abscess as a result of mesothelial damage caused by burning effect of different instruments. Postoperative intraabdominal abscess incidence is thrice as high in laparoscopic appendectomy compared to open appendectomy. ${ }^{10,13,14}$ Infection being one of the complications of laparoscopic appendectomy presents with symptoms of pelvic, right lower quadrant, or diffuse abdominal pain, with variable severity of tenderness or frank peritonitis, hypotension, nausea, and fever. ${ }^{15}$ In a research conducted at Bangladesh it was observed that port-site bleeding and infection were in $4.3 \%$ and $2.1 \%$, respectively. ${ }^{16}$ Port site incisional hernia is the complication of single incisional laparoscopic surgery that is $2.9 \%$ according to the study that was conducted at tertiary center in Bronx, New York. ${ }^{17}$

Histopathological examination of the appendix serves two purposes. First, it allows the diagnosis of acute appendicitis to be confirmed, especially where this is not evident intra-operatively. Second, histopathological examination may disclose additional pathologies that may not be evident on gross examination intraoperatively but may affect subsequent clinical management of the patient. Five pathological groups with consequential diagnoses may be encountered in appendices specimens: parasite infection, endometriosis, granulomatosis, benign neoplasm, and premalignant / malignant neoplasm. A retrospective study conducted in Department of Pathology of CHU Habib Bourguiba, Sfax, Tunisia, showed that perforated appendicitis were noted in $1,239(6.3 \%)$ cases. Intraluminal Enterobius vermicularis were present in 1,599 (6.4\%) cases; $693(43.3 \%)$ of these were associated with acute inflammation of the appendicular wall; neoplastic lesions were present in $171(0.6 \%)$ cases. $^{18}$

The objective of the study was to determine the spectrum of postoperative complications and histopathological findings of appendectomy at a tertiary are hospital of Peshawar, Khyber Pakhtunkhwa, Pakistan, based on analysis of archival data.

\section{MATERIALS \& METHODS}

This descriptive case series was conducted in the Department of Surgery, Rehman Medical Institute, Peshawar, from January to February 2019 on archival data retrieved for the years 2017-2018.
All 130 cases of acute appendicitis in which appendectomy was performed in Rehman Medical Institute, Peshawar were included. Patients having dual pathologies, any malignancy, gynecological problem and renal abnormalities were excluded.

A structured Performa was used to collect relevant data about postoperative complications and histopathological findings of appendectomy; the Performa consisted of demographic data, symptoms, complications, investigations performed, preoperative position of appendix, pathology and comorbidities.

Data were analyzed for descriptive statistics using SPSS 25.0.

\section{RESULTS}

Of 130 cases, there were $73(56.15 \%)$ males and 57(43.85\%) females. The ages varied widely, with age 19 years being more common $(06.9 \%)$, followed by age 40 years $(06.2 \%)$. Presenting complaints of patients are shown in Figure 1.

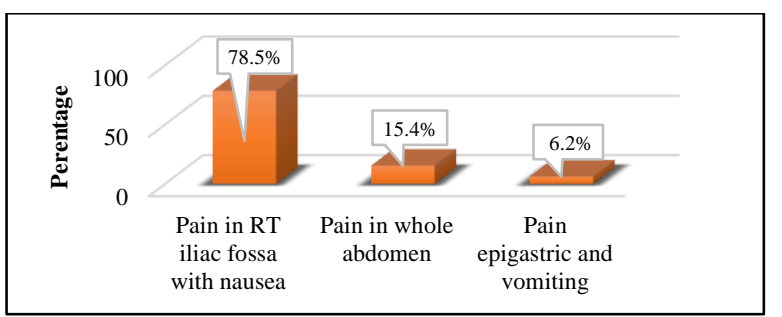

Figure 1: Presenting complaints of patients undergoing appendectomy $(\mathrm{n}=130)$.

Preoperative position of the appendix was retrocecal in most cases $(75.4 \%)$ followed by Pelvic (15.4\%); other positions were in minor percentages as shown in Figure 2.

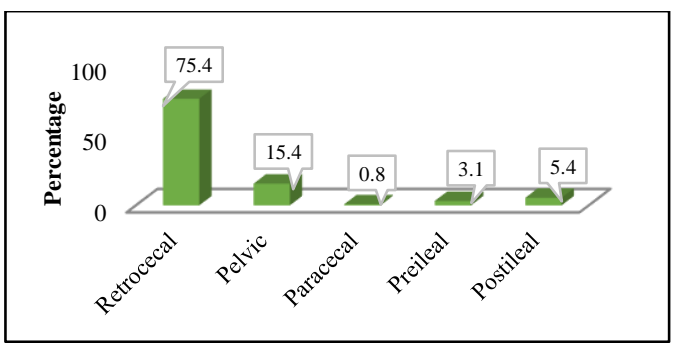

Figure 2: Preoperative position of vermiform appendix in patients undergoing appendectomy $(n=130)$.

Regarding investigations, $95.4 \%$ patients had total leucocyte counts (TLC), ultrasound abdomen, and CT scans of abdomen and pelvis done, while $4.6 \%$ had only CT scans of abdomen and pelvis done (Figure 3 ).

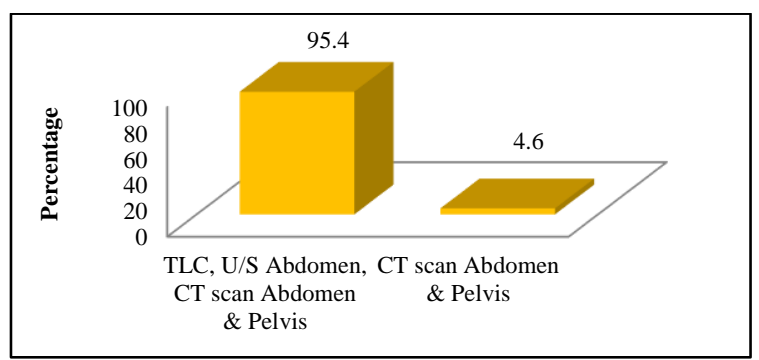

Figure 3: Preoperative investigations done in patients undergoing Appendectomy ( $n=130)$. 
There were no postoperative complications in $52.3 \%$ of patients; the remaining patients had Wound Infection as the major complication $(25.4 \%)$, followed by Peritonitis $(06.2 \%)$, intraabdominal collection (02.3\%), and Generalized Sepsis (01.5\%), as shown in Figure 4.

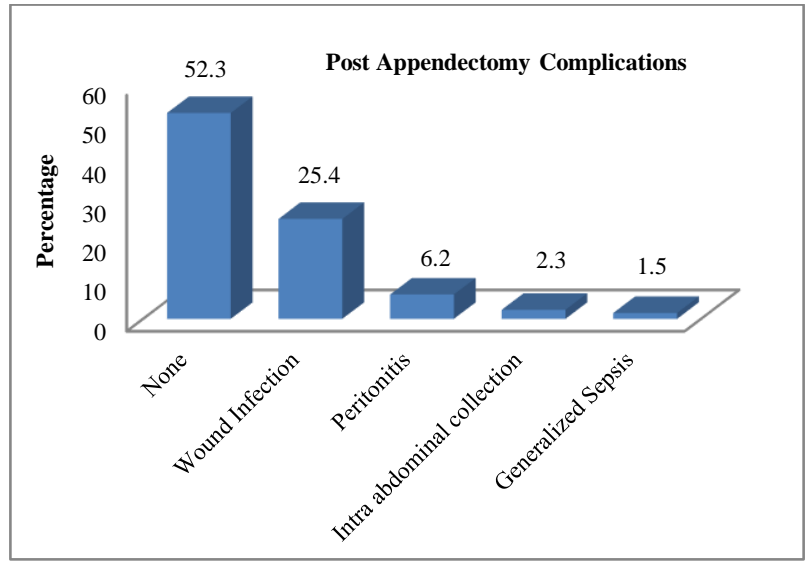

Figure 4: Postoperative complications in patients undergoing appendectomy $(\mathrm{n}=130)$.

Other non-septic complications are shown in Figure 5.

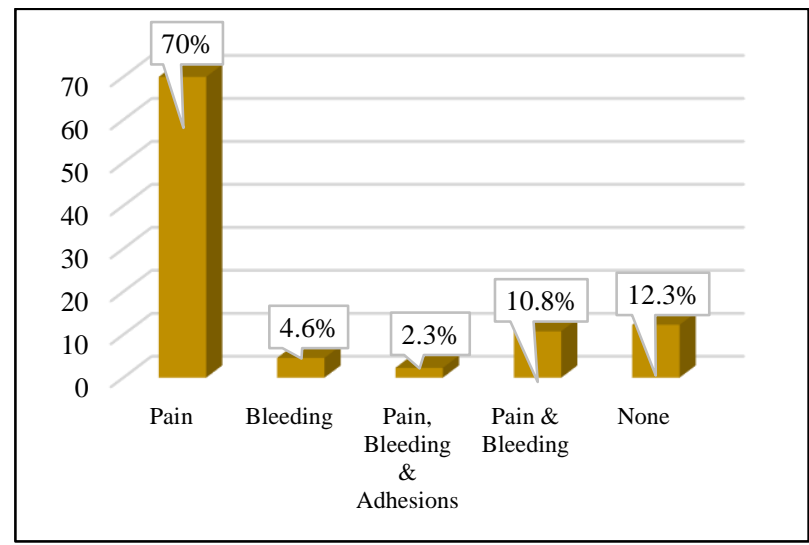

Figure 5: Non Septic complications in patients undergoing appendectomy $(\mathrm{n}=130)$.

\section{DISCUSSION}

Acute appendicitis remains one of the most common surgical conditions leading to emergency operation. ${ }^{19}$ The possibility of appendicitis must be considered in any patient presenting with an acute abdomen, and a certain preoperative diagnosis is still a challenge. ${ }^{20}$ In our study the most common age group was 19 years $(n=9) 6.9 \%$ followed by 40 years $(n=8) 6.2 \%$. This somehow matches the literature in which Appendicitis is most common between the ages of 10 and 20 years, but no age is exempt. ${ }^{21}$

In our study there was a preponderance of males having a percentage of $56.2 \%(n=73 / 130)$ compared to the females having a percentage of $43.8 \%(n=57 / 130)$. Similar results were observed in another study conducted by Drake FT and Naderan M. ${ }^{22,23}$ According to Naderan et al that one of the possible explanations for the preponderance of the males could be that the women were referred to a gynecologist due to a common complaint of pain in abdomen for many of their gynecological problems.

All the patients included in our study presented with the common complaint of pain in right iliac fossa with nausea, $78.5 \%(\mathrm{n}=$ $102 / 130$ ), followed by generalized abdominal pain that was $15.4 \%(n=20)$ and epigastric pain and vomiting with a percentage of $6.2 \%(\mathrm{n}=8)$. This co-relates with a study conducted in year 2018, which showed that migrating pain in the abdomen (67.8\%) was the most common symptom of patient with acute appendicitis in the non-perforated group and $80.5 \%$ in the perforated group. ${ }^{2}$ Another study conducted by Ibrahim Salih Elkheir et al showed that right iliac fossa pain was found in all patients. ${ }^{1}$ These results were similar to that done by Mike Hardin, in which right iliac fossa tenderness was found in $94.4 \% .{ }^{24}$ Other symptoms included were; anorexia, vomiting, fever, ${ }^{1,2}$ and rebound tenderness. ${ }^{24}$

Appendix has many different anatomical sites, in our study we found that Retrocaecal appendix is the most frequent site $75.4 \%$, which correlates with a study conducted in year 2016 that showed $73.9 \%$ of appendix were Retrocaecal. ${ }^{1}$

The most common laboratory finding in our study was total WBC count along with radiological intervention that included Ultrasound abdomen and CT scan abdomen and pelvis similar to a study conducted by Juma Obayashi et al. ${ }^{25}$

Complicated acute appendicitis was diagnosed in $94.3 \%$ and in those the most frequent was appendicular mass $45.2 \%$ which diagnosed either clinically or radiologically using ultrasound, or these incidences were much higher than reported in Nigeria. ${ }^{1,21}$

In the current study, $52.3 \%$ of patients did not develop any postoperative complication while $47.7 \%$ developed complications including wound infection $25.4 \%$, peritonitis $6.2 \%$, generalized sepsis $5.4 \%$ and intra-abdominal collection $2.3 \%$ while histopathological studies showed that only $0.8 \%$ patients developed mucinous lesions. Other non-septic complications include pain (70\%), pain and bleeding $(10.8 \%)$ and adhesions (2.3\%). As compared to another study, the most common postoperative complications were post site bleeding (4.3\%) and wound infection $(2.1 \%)^{16}$ while one study showed no postoperative complications. ${ }^{1}$

\section{CONCLUSION}

Acute Appendicitis was more in male patients presenting as pain in the right iliac fossa; raised total leucocyte count, Ultrasound abdomen and CT scan abdomen and pelvis were helpful diagnostic modalities. Retrocecal location of appendix was the mode, and wound infection and pain were the commonest complications after surgery. 


\section{REFERENCES}

1. Elkheir BS, Ahmed S, Yassin FSA. Incidence and prevalence of acute appendicitis at Khartoum North teaching hospital from March 2013-November 2015. Sch J App Med Sci. 2016; 4(6C):2045-7.

2. Iamarino APM, Juliano Y, Rosa OM, Novo NF, Favaro ML, Augusto M, et al. Risk factors associated with complications of acute appendicitis. Rev Col Bras Cir 2017; 44(6): 560-6.

3. Simpson J, Samaraweera AP, Sara RK, Lobo DN. Acute appendicitis-a benign disease?. Ann R Coll Surg Engl. 2008 May;90(4):313-6.

4. Xiao Y, Shi G, Zhang J, Cao JG, Liu LJ, Chen TH, et al. Surgical site infection after laparoscopic and open appendectomy: a multicenter large consecutive cohort study. Surg Endosc. 2015 Jun;29(6):1384-93.

5. Cipe G, Idiz O, Hasbahceci M, Bozkurt S, Kadioglu H, Coskun H, et al. Laparoscopic versus open appendectomy: where are we now. Chirurgia (Bucur). Jul-Aug 2014;109(4):518-22

6. Chandrashekar S, Lokesh MG, Avinash SR. Prevalence of perforated appendicitis and its determinants in pediatric appendicitis patients admitted in tertiary care centre, South India: a cross sectional study. Int Surg J. 2018 Nov 28;5(12):39269.

7. Esposito C, Calvo AI, Castagnetti M, Alicchio F, Suarez C, Giurin I, et al. Open versus laparoscopic appendectomy in the pediatric population: a literature review and analysis of complications. J Laparoendosc Adv Surg Tech. 2012 Oct 1;22(8):834-9.

8. Horwitz JR, Custer MD, May BH, Mehall JR, Lally KP. Should laparoscopic appendectomy be avoided for complicated appendicitis in children? J Pediatr Surg. 1997 Nov 1;32(11):1601-3.

9. Tang E, Ortega AE, Anthone GJ, Beart RW. Intraabdominal abscesses following laparoscopic and open appendectomies. Surg Endosc. 1996 Mar 1;10(3):327-8.

10. Serour F, Witzling M, Gorenstein A. Is laparoscopic appendectomy in children associated with an uncommon postoperative complication? Surg Endosc. 2005 Jul 1;19(7):919-22.

11. Markar SR, Blackburn S, Cobb R, Karthikesalingam A, Evans J, Kinross J, Faiz O. Laparoscopic versus open appendectomy for complicated and uncomplicated appendicitis in children. $\mathrm{J}$ Gastrointest Surg. 2012 Oct 1;16(10):19932004.

12. Krisher SL, Browne A, Dibbins A, Tkacz $\mathrm{N}$, Curci M. Intra-abdominal abscess after laparoscopic appendectomy for perforated appendicitis. Arch Surg. 2001 Apr 1;136(4):438-41.

13. Ohtani H, Tamamori $\mathrm{Y}$, Arimoto $\mathrm{Y}$, Nishiguchi Y, Maeda K, Hirakawa K. Meta-analysis of the results of randomized controlled trials that compared laparoscopic and open surgery for acute appendicitis. J Gastrointest Surg. 2012 Oct 1;16(10):1929-39.

14. Li X, Zhang J, Sang L, Zhang W, Chu Z, Li $X$, et al. Laparoscopic versus conventional appendectomy-a meta-analysis of randomized controlled trials. BMC Gastroenterol. 2010 Dec;10(1):129.

15. McKinlay R, Neeleman S, Klein R, Stevens $\mathrm{K}$, Greenfeld J, Ghory $\mathrm{M}$, et al. Intraabdominal abscess following open and laparoscopic appendectomy in the pediatric population. Surg Endosc. 2003 May 1;17(5):730-3.

16. Maitra TK, Ekramullah M, Mondol SK. Post-surgical outcomes of laparoscopic appendectomy observed at BIRDEM hospital. IMCJMS. 2017 Mar 22;11(1):158 .

17. Agaba EA, Rainville $\mathrm{H}$, Ikedilo $\mathrm{O}$, Vemulapali P. Incidence of port-site incisional hernia after single-incision laparoscopic surgery. JSLS. 2014 Apr;18(2):204-10.

18. Charfi S, Sellami A, Affes A, Yaïch K, Mzali R, Boudawara TS. Histopathological findings in appendectomy specimens: a study of 24,697 cases. Int J Colorectal Dis 2014 Aug 1;29(8):1009-12.

19. Chamisa I. A clinicopathological review of 324 appendices removed for acute appendicitis in Durban, South Africa: a retrospective analysis. Ann R Coll Surg Engl. 2009 Nov;91(8):688-92.

20. Biondi A, Di Stefano C, Ferrara F, Bellia A, Vacante M, Piazza L. Laparoscopic versus open appendectomy: a retrospective cohort study assessing outcomes and costeffectiveness. World J Emerg Surg. 2016 Dec;11(1):44.

21. Singh M, Kadian YS, Rattan KN, Jangra B. Complicated appendicitis: analysis of risk factors in children. Afr J Paediatr Surg. 2014 Apr 1;11(2):109-13.

22. Drake FT, Mottey NE, Farrokhi ET, Florence MG, Johnson MG, Mock C, et al. Time to appendectomy and risk of perforation in acute appendicitis. JAMA Surg. 2014 Aug 1;149(8):837-44.

23. Naderan M, Babaki AE, Shoar S, Mahmoodzadeh H, Nasiri S, Khorgami Z. Risk factors for the development of complicated appendicitis in adults. Ulus Cerrahi Derg. 2016;32(1):37-42.

24. Roach JP, Partrick DA, Bruny JL, Allshouse MJ, Karrer FM, Ziegler MM. Complicated appendicitis in children: a clear role for drainage and delayed appendectomy. Am J Surg. 2007 Dec 1;194(6):769-73.

25. Obayashi J, Ohyama K, Manabe S, Tanaka K, Nagae H, Shima H, et al. Are there reliable indicators predicting postoperative complications in acute appendicitis? Pediatr Surg Int. 2015 Dec 1;31(12):1189-93. 